\title{
Lung cancer screening: 360 degree review
}

\author{
Christian J Herold ${ }^{1 *}$, Theresa C McLoud ${ }^{2}$ \\ From International Cancer Imaging Society Meeting and 15th Annual Teaching Course (ICIS 2015) \\ London, UK. 5-7 October 2015
}

The most compelling evidence supporting the use of low dose computed tomography in the screening of high risk populations for lung cancer was generated by the National Lung Cancer Screening Trial carried out in the United States by the National Cancer Institute and the American College of Radiology Imaging Network.[1] This trial was a randomized prospective study which included over 53,000 participants. The two arms consisted of patients who were randomized to low dose $\mathrm{CT}$ and those who received standard radiography. Data from the NLST demonstrated that screening reduced mortality by $20 \%$ in the CT $\mathrm{arm}$. Other smaller studies carried out in Europe have reported no mortality benefit. However, these studies included a younger screening population and had a smaller number of participants and probably did not have the power to show a mortality benefit.[2] Major medical societies and US government agencies such as US Preventative Services Task Force and now the Center for Medicare Services have now recommended LDCT. These decisions not only recommend screening but require US insurance companies and Medicare in the US to provide reimbursement.[3]

Some of the caveats of screening result from the limits of generalization of the NLST results based on risk groups and demographics. There are also potential harms and complications from the LDCT screening which include radiation exposure, over diagnosis, the use of invasive procedures for diagnosis and the high false positive rate. $[1,4]$

Lung cancer screening could have a strong impact on health care in Europe where there are over 268,000 lung cancer deaths per annum. Screening could save thousands of lives. However, lung cancer screening is currently not reimbursed and there are no screening programs accessible through health care systems or health plans. Important factors for lung cancer screening in Europe include refinement of inclusion criteria and

${ }^{1}$ Department of Biomedical Imaging and Image Guided Therapy, Medical University of Vienna / AKH, Vienna, Austria

Full list of author information is available at the end of the article stratification of risks, modeling of cost effectiveness data, and inclusion of evidence from European trials. Implementation of screening programs in Europe will require a collaborative effort among professional specialties, societies, organizations, and additional trial data.

The American College of Radiology has developed a reporting system for lung cancer screening designated "Lung Rads." [5] It is a reporting system which is very similar to Bi-Rads that includes numeric categories. It associates CT findings with guideline based management decisions. LDCT findings are categorized from 1-4 according to the likelihood of malignancy. 1 and 2 are considered benign findings and 3 and 4 have a higher probability of malignancy. There are descriptions for each of the 4 categories plus an enumeration of findings. The categories include characterization of nodules including size and density (solid, part-solid, or nonsolid ground glass). In addition to the categories and findings there are guidelines for management in each category with estimates of the probability of malignancy and the estimated population prevalence.

Constructing a lung cancer screening program in your institution presents many challenges. (6) Stake holders include the hospital leadership, referral providers, a multidisciplinary team, and support staff. Patient and physician outreach and education are essential. Standard protocols should be developed for image acquisition. Ideally image review should be performed by radiologists experienced in chest $\mathrm{CT}$ and nodule detection. Imaging software that combines $\mathrm{CAD}$ and volumetric measurements is desirable. Findings should be recorded according to the lung imaging reporting and data system such as Lung Rads. Communication of results to both the patient and physician is important and such communication should be stratified according to urgency.

\section{Authors' details}

${ }^{1}$ Department of Biomedical Imaging and Image Guided Therapy, Medical University of Vienna / AKH, Vienna, Austria. ${ }^{2}$ Department of Radiology, 
Published: 2 October 2015

\section{References}

1. Aberle DR, Adams AM, Berg CD, et al: National Lung Screening Trial Research Team. Reduced lung-cancer mortality with low-dose computed tomographic screening. N Engl J Med 2011, 365:395-409.

2. Infante M, Cavuto S, Lutman FR, et al: DANTE Study Group. A randomized study of lung cancer screening with spiral computed tomography: 3year results from the DANTE trial. Am J Respir Crit Care Med 2009, 180:445-453.

3. Decision Memo for Screening for Lung Cancer with Computed Tomography (LDCT)(CAG-00439N). , available at CMS.gov http://www.cms. gov/medicare-coverage-database/details/nca-decision-memo.aspx? NCAld $=274$.

4. Bach P: Overdiagnosis in lung cancer: Different perspectives, definitions and implications. Thorax 2008, 63:298-300.

5. , http://www.acr.org/ /media/ACR/Documents/PDF/QualitySafety/ Resources/LungRADS/AssessmentCategories.pdf (ACR Document).

6. Fintelmann F, Bernheim A, Digumarthy S, et al: The 10 Pillars of Lung Cancer Screening: Rationale and Logistics of a Lung Cancer Screening Program. Radiographics 2015.

doi:10.1186/1470-7330-15-S1-013

Cite this article as: Herold and McLoud: Lung cancer screening: 360 degree review. Cancer Imaging 2015 15(Suppl 1):013.

\section{Submit your next manuscript to BioMed Central} and take full advantage of:

- Convenient online submission

- Thorough peer review

- No space constraints or color figure charges

- Immediate publication on acceptance

- Inclusion in PubMed, CAS, Scopus and Google Scholar

- Research which is freely available for redistribution

Submit your manuscript at www.biomedcentral.com/submit 